\title{
DIREITOS HUMANOS E O ACESSO Â MACONHA MEDICINAL PARA FORNECIMENTO GRATUITO DE MEDICAMENTOS PELO SUS: um estudo de caso da Ação Civil Pública $n^{\circ}$ 0802271-83.2015.4.05.8200'
}

\author{
Lucas Lopes Oliveira ${ }^{2}$
}

Luziana Ramalho Ribeiro ${ }^{3}$

Palavras-Chave

Maconha medicinal/ Direitos

Humanos/ Fornecimento de

medicamentos

\section{SUMÁRIO}

1. Introdução. 2. A emergência de contradiscursos sobre a maconha. 3 Inquérito Civil Público n 1.24.000.001421/2014-74- Ação Civil Pública n 0802271-83.2015.4.05.8200. 4. Uma conclusão a se construir: a tutela da maconha medicinal entre a judicialização de medicamentos e a autoprodução.

\footnotetext{
O presente trabalho foi realizado com apoio da Coordenação de Aperfeiçoamento de Pessoal de Nível Superior - Brasil (CAPES) - Código de Financiamento 001.

2 Mestre em Direitos Humanos, Cidadania e Políticas Públicas. Dou torando em Ciências Jurídicas.

3 Doutora em Sociologia. Professora do Programa de Pós-Graduação em Direitos Humanos, Cidadania e Políticas Públicas da Universidade
} Federal da Paraíba.

\section{Resumo}

O presente estudo analisa a judicialização do direito ao acesso à maconha medicinal a partir de ações judiciais que visam ao fornecimento de medicamentos à base de maconha pelo Sistema Único de Saúde (SUS). Trata-se, portanto de uma pesquisa sociojurídica qualitativa de base documental analisada sob o viés foucaultiano da análise de discurso. Como estratégia de pesquisa utilizamos um estudo de caso de uma emblemática Ação Civil Pública proposta pelo Ministério Público Federal da Paraíba. Nosso objetivo foi explorar as possibilidades e os limites da efetivação dos direitos humanos de pacientes que demandam o uso de maconha medicinal frente a tal forma de judicalização deste acesso. Trabalhamos a hipótese de que tal ação se mostra ainda à mercê de grande insegurança jurídica. Ao final, realizamos a contextualização de tal ação dentro de uma problematização maior de judicialização do direito ao acesso à maconha medicinal a partir de uma crítica aos entraves legais que permeiam o acesso à maconha medicinal no Brasil. 


\section{HUMAN RIGHTS AND THE ACCESS TO MEDICINAL MARIJUANA FOR FREE MEDICINE PROVISION BY SUS: a case study on the civil action $n^{\circ}$ 0802271-83.2015.4.05.8200}

Lucas Lopes Oliveira

Luziana Ramalho Ribeiro

\section{KEYWORDS}

Medicinal marijuana/ Human rights/ Medicine provision.

\begin{abstract}
This study analyses the judicialization of the right to access medicinal marijuana based on judicial actions that seek the provision of medicines made from marijuana by the SUS. This is, therefore, a qualitative social and juridical research based on documents analysed from Foucault's discourse analysis point of view. As our research strategy, we use a study case of an emblematic Public Civil Action proposed by the Paraíba's Federal Public Ministry. Our objective was to explore the possibilities and the limits of actualizing the human rights of patients who demand medicinal marijuana before such a way of judicializing this access. We work on the hypothesis that such action is still at mercy of great juridical uncertainty. Finally, we contextualize such action into a bigger concern on the judicialization of the right to access medicinal marijuana by criticizing the legal barriers that permeate the access to medicinal marijuana in Brazil.
\end{abstract}




\section{Introdução}

O presente trabalho trata-se de um recorte de um estudo dissertativo de mestrado que investigou as possibilidades de ruptura com o modelo proibicionista de gestão da política de drogas no Brasil. No referido capítulo do texto dissertativo - aqui convertido em artigo, revisado e atualizado - investigamos o processo de judicialização do direito ao acesso à maconha medicinal no Brasil, através de um emblemático caso ocorrido na Paraíba.

Nosso objetivo nesse artigo é analisar o enfrentamento judicial proposto pela luta de pacientes em defesa do direito ao acesso à maconha medicinal na Paraíba, observando a construção judicial do direito humano à saúde de pacientes que dependem de um tratamento médico com base em derivados da maconha. Para tanto, escolhemos uma das formas de judicialização do acesso à maconha medicinal no estado. Estudaremos os limites e as possibilidades desta ação, bem como, o déficit de efetividade do direito à saúde e a ausência de segurança jurídica no que diz respeito a esta problemática.

Para tanto, traremos em um primeiro momento uma reflexão sobre o proibicionismo enquanto regime de verdade e seus contornos que implicam uma discussão sobre os direitos humanos. Em seguida, passamos a explorar os discursos de crítica ao proibicionismo, no intuito de desenvolver a possibilidade de outras formas de regulação sobre o uso de drogas. As demandas dos movimentos sociais reclamam a regulamentação do uso e do cultivo da cannabis, a descriminalização de condutas relacionadas ao uso de drogas, a diminuição do encarceramento por crimes relacionados à Lei de Drogas e políticas públicas de acesso à cannabis para fins terapêuticos. Estes discursos expressam as vozes dos movimentos sociais e sua não sujeição ao status quo. Entre estes vários discursos de enfrentamento, escolheremos, para analisar neste artigo, o discurso que se orienta pelo uso medicinal da maconha.

Como expressão do discurso em defesa da maconha medicinal, nos interessa especialmente a sua dimensão expressa na prática jurídica do processo de judicialização do direito ao uso da maconha medicinal como uma questão de acesso à saúde. Escolheremos, portanto, a atuação judicial e extrajudicial do MPF-PB na luta em defesa do direito ao acesso à maconha medicinal. Esta atuação está expressa em petições judiciais, atas de reuniões, sentenças judiciais e demais documentos que expressam a luta institucional pelo acesso à maconha medicinal realizada pelo MPF-PB em defesa de pacientes que dependem da maconha medicinal. Para a obtenção destes dados documentais entramos em contato com o MPF-PB na busca de documentos que representem sua atuação ao longo do Inquérito Civil Público n 1.24.000.001421/2014-74 e da Ação Civil Pública n 0802271-83.2015.4.05.8200, que expressam, respectivamente, a atuação extrajudicial e judicial do MPF na defesa dos direitos humanos de pacientes de maconha medicinal.

Faremos também a análise desta ação em um contexto mais amplo de judicialização do acesso à maconha medicinal no Brasil, identificando os limites que a judicialização de demandas judiciais que visam ao fornecimento gratuito de medicamentos encontram em virtude da insegurança jurídica e dos custos elevados da importação pelo Sistema Único de Saúde - SUS em um contexto de crise fiscal do Estado. 
A análise da referida ação, sua importância e os seus limites, torna-se, também, importante por trazer à tona o debate sobre o atual contexto regulatório da maconha medicinal no Brasil. $O$ acesso a remédios à base de maconha ainda depende, em larga medida, de provimentos judiciais, sem marcos legais sólidos sobre o direito ao cultivo e a produção de remédios, seja por pessoas individualmente, seja por associações ou por agentes econômicos.

O referido estudo alinha-se à crítica dos discursos científicos a partir de uma perspectiva genealógica foucaultiana (FOUCAULT, 1999). Tendemos, portanto, a analisar politicamente o discurso, dito científico, enquanto produtor de relações de saber-poder. Descartamos a ideia de neutralidade científica e, a partir da demonstração da parcialidade dos discursos, observaremos as possibilidades de enfrentamento, de contradiscusos e de fissuras. Isto será feito a partir da análise dos focos de tensão dentro dos discursos médicos e jurídicos que constituem a reconfiguração deste campo de luta social.

Logo, a referida pesquisa trata-se de uma pesquisa qualitativa e de estudo de caso sobre o direito ao acesso à maconha medicinal no Brasil. A partir de uma análise de discurso, sob os marcos do pensamento de Michel Foucault (2013). Utilizaremos a forma narrativa como método de estruturação dos discursos aqui expressos.

\section{A emergência de contradiscursos sobre a maconha}

Michel Foucault já delimitava uma forma de controle que emerge ao longo da modernidade e que impunha um controle que se voltou ao corpo humano e ao corpo so- cial da população numa nova economia do controle e da vigilância populacional (Foucault, 2013; 2014). Este poder, que utilizará mecanismos jurídicos e disciplinares, reconfigurando sua lógica, foi chamado, por Michel Foucault, de biopoder (1999; 2014). Desse modo, trabalhamos com a hipótese de que a criminalização das drogas constitui-se como uma importante ferramenta da biopolítica no século XX, a partir do agregamento entre os discursos médicos e jurídicos que tornará a saúde um objeto de intervenção crescente que resultará em uma normalização dos hábitos da população (Foucault, 2002). É assim que se estrutura um mecanismo transnacional de controle sobre as drogas (Rodrigues, 2008).

A reestruturação do poder político a partir da entrada em cena da população, no chamado processo de redemocratização brasileiro (Cf. Zaluar, 1998) fez emergir novas formas de controle social a partir do discurso da segurança pública. A criminalização das drogas no Brasil resultou em sérios problemas relacionados aos direitos humanos 0 . Como exemplo, o super encarceramento devido a condenações criminais envolvendo crimes relacionados a drogas no Brasil é algo bastante denunciado pela criminologia crítica (Carvalho, 2013). Segundo dados do Ministério da Justiça o número de incidências de crimes previstos na Lei de Drogas na população carcerária no Brasil é de 176.691. Isto corresponde a 155.669 incidências na população carcerária masculina e 21.022 na população feminina, totalizando $29 \%$ das incidências na população carcerária masculina e 62 \% de incidência na população carcerária feminina (Brasil, 2017). Destaca-se, a partir destes dados, que a criminalização das drogas é a maior causa de aprisionamento entre as mulheres e a segunda maior 
entre os homens. Parte das pessoas presas por drogas no Brasil desafiam a imagem estereotipada do traficante como inimigo público número um. Estas pessoas são, muitas vezes, vítimas de processos de exclusão. São em sua maioria réus primários, sem antecedentes criminais, pegos desarmados (CastiIho et ali, 2009; Boiteux, 2014). Além disto, a maior parte é formada por negros e/ou pardos (Jesus, 2011). Salta aos olhos também a quantidade crescente de mulheres presas por tráfico de drogas, conforme expresso por Boiteux (2014).

Ainda é preocupante que a Lei $n^{\circ} 11.343 / 2006$, conhecida como Lei de Drogas, não apresente critérios seguros no que diz respeito à diferenciação entre usuários e traficantes, sendo este critério de natureza essencialmente subjetiva que reproduz preconceitos sociais, presentes no imaginário do julgador, na hora da aplicação da lei. Por este motivo boa parte das pessoas presas por tráfico no Brasil teria sido considerada usuárias segundo a lei de outros países: os percentuais chegam a 69\% das pessoas presas por maconha em caso de aplicação da legislação espanhola sobre drogas, conforme pesquisa de Juliana Carlos (2015).

Todas estas questões nos abrem os olhos para um processo de criminalização da pobreza, encarceramento em massa de pessoas em estado de vulnerabilidade social que não apresentam qualquer risco social e que são encarcerados por uma guerra às drogas já perdida.

A partir desta crítica à política de drogas, muitos movimentos sociais acabaram por contestar este paradigma proibitivo. As Marchas da Maconha se inspirando em um movimento global: Global Marijuana March, da década de 1990, cuja primeira edição no
Brasil ocorreu na cidade do Rio de Janeiro em 2002 (Pinto \& Paulino, 2013), rapidamente se espalhou para outras cidades e se tornou um dos principais movimentos sociais do Brasil e que articulam a partir da estética das manifestações de ruas, performances divergentes (cf. Salih, 2017) que propunham um novo olhar sobre a política de drogas, mostrando a necessidade de descriminalização e legalização da maconha (Delmanto, 2013). Além das marchas de caráter mais esporádico e com foco em regulamentação da maconha, o movimento antiproibicionista surge na luta por mudanças profundas nas políticas públicas e pela revisão do paradigma proibicionista. Dada à pluralidade de concepções existentes dentro do(s) movimento(s) antiproibicionista(s) vemos uma gama de propostas que se unem a partir de uma crítica ao atual modelo de gestão das políticas sobre drogas.

A partir de uma tentativa de criminalização da Marcha da Maconha, o STF julgou a constitucionalidade da mesma, como expressão do direito à liberdade de manifestação e expressão. A partir deste reconhecimento a visibilidade do movimento social pela mudança na Lei de Drogas ganha cada vez mais destaque (Oliveira \& Ribeiro, 2016; Pinto \& Paulino, 2013).

É neste contexto que emerge a campanha "Repense" e o documentário "llegal" de Tarso Araújo (2014). A campanha e o documentário visavam trazer à tona a discursão sobre o uso medicinal da cannabis. O documentário expõe as narrativas de pessoas que precisam recorrer aos canabinoides extraídos da maconha para o tratamento de suas patologias. Teve destaque a história da menina Anny Fischer, que possuía epilepsia refratária aos tratamentos convencionais e que, empiricamente, teve respostas positi- 
vas com os remédios derivados de maconha, traduzindo em melhor qualidade de vida.

Neste contexto, o movimento pelo direito ao acesso à maconha medicinal ganhou destaque nacional e se articulou em rede conseguindo várias vitórias no sentido de mudança na percepção popular sobre a maconha. A articulação nas Marchas da Maconha destacam as convergências entre a luta do movimento antiproibicionista e a luta pelo direito ao acesso à maconha medicinal.

Os movimentos sociais tiveram um importante papel no Estado da Paraíba. Conforme estudos de Oliveira \& Ribeiro (2017) a Paraíba teve o primeiro caso de uma vitória coletiva que conseguiu a declaração judicial de autorização da importação de produtos à base de canabinoides, durante o ano de 2014.

A partir desta derrota judicial e de outras mais que se proliferaram - a exemplo da sentença que concedeu o direito de importar à Anny Fischer - a Agência Nacional de Vigilância Sanitária (ANVISA), acabou pressionada a tomar uma decisão que a autarquia tinha adiado, por motivos políticos conservadores evidentes, que seria a decisão de reclassificação do canabidiol de substância proscrita para substância de uso controlado. Neste sentido, inaugurou-se um novo regime em termos de regulamentação para produtos à base de CBD que prometia maior agilidade burocrática neste processo.

Ocorre que, apesar dos avanços reais em termos de burocracia e das promessas não cumpridas no que diz respeito à democratização do acesso aos compostos à base da cannabis, mesmo com a regulamentação deste processo de importação, as famílias continuaram a ter dificuldades ao acesso. Destacamos, com base em nosso estudo empírico documental, como a principal dificuldade o custo de importação destes medicamentos que poderiam chagar a cifra de alguns milhares de reais de custo por mês, algo impraticável para a maioria dos brasileiros.

Será neste contexto que retomaremos a narrativa do direito ao acesso à maconha medicinal travada pelas famílias do Estado da Paraíba. Partimos da análise da atuação judicial e extrajudicial da Procuradoria Federal dos Direitos do Cidadão (PFDC) vinculada ao Ministério Público Federal da Paraíba (MPF) a partir de documentos pesquisados junto ao órgão. Neste artigo, recorte de um trabalho maior, tomamos como base a atuação da Procuradoria Federal dos Direitos do Cidadão (PFDC) em momento posterior à reclassificação do CBD, fato que regulamentou a possibilidade de importação. Mas esta mudança, apesar de um significativo avanço, não eliminou as barreiras e entraves ao acesso. Foi com as novas demandas advindas desta nova realidade que os militantes pelo acesso à maconha medicinal no Estado da Paraíba levaram à PFDC e a partir desta atuação que traçamos a análise da Ação Civil Pública n 0802271-83.2015.4.05.8200.

\section{Inquérito Civil Público n 1.24.000.001421/2014-74- Ação Civil Públi- ca n 0802271-83.2015.4.05.8200}

É neste contexto que emerge a Ação $\mathrm{Ci}$ vil Pública que estudaremos no presente texto. Um contexto de enfrentamento ao discurso proibicionista que relegava a maconha à proscrição. Este enfrentamento é viabilizado pela luta dos pacientes e de seus familiares em defesa do direito ao acesso à maconha medicinal. A luta pelo acesso à maconha medicinal conseguiu mobilizar importantes argumentos tanto do regime 
de verdade médico, como do regime de verdade jurídico. Estes argumentos foram instrumentalizados contra as velhas estruturas discursivas dos discursos médicos e jurídicos, promovendo a reconfiguração destes regimes de verdade. Esta reconfiguração discursiva abre caminho para reconfigurações das práticas de poder a partir da instrumentalização de saberes científicos outros - tanto saberes médicos quanto saberes jurídicos - contra "O Saber" científico hegemônico proibicionista. A maconha deixa de ser vista como uma substância perigosíssima que deve ser criminalizada e passa a ser vista como remédio. Esta reconfiguração é vista a partir dos discursos de médicos que atestam o poder terapêutico da maconha e que adentram no judiciário a partir da retórica da luta por direitos humanos.

Após várias derrotas judiciais a ANVISA reclassificou o canabidiol, que deixou de ser substância proscrita e se tornou substância de uso controlado. A Resolução RDC n 17 da ANVISA, de 6 de maio de 2015, trouxe novas regras para importação de medicamentos feitos à base de canabidiol. Destaca-se que esta importação, segundo a referida normatização deveria se dá de modo excepcional e sob critérios rígidos de controle por parte da autarquia sanitária - algo bastante criticado pelos usuários e pacientes, pois dificultava bastante o acesso. Então, neste momento inicial de nossa narrativa, como única possibilidade legal de acesso havia apenas a importação de remédios à base de CBD a alto custo e cujo procedimento era extremamente burocrático e demorado. Entre estes critérios estão o prévio cadastramento do interessado na ANVISA, de acordo com os artigos 7 e 8 da referida resolução, e a obediência procedimentos fiscais a aduaneiros.

Destacamos cinco produtos que se enqua-

dravam, naquele momento, nos requisitos estabelecidos pela portaria recém lançada pela ANVISA (BRASIL, 2014), - a) com quantidade menor de canabidiol (CBD) do que Tetraidrocanabinol (THC); b) produzidos e distribuídos por estabelecimentos regularizados pela autoridade competentes em seus países de origem; c) certificado de análises com teor do CBD e THC conforme exigências regulatórias de seus países de origem - encontravam-se os seguintes produtos sugeridos pela ANVISA no texto do referido documento: "Cibdez Hemp CBD complex (gotas) 1 a 2oz; Cibdex Hemp CBD complex (cápsulas); Hemp CBD Oil 200mg Canabidiol - 240mL; Real Scientific Hemp Oil (RSHO) CBD 14-25\% 3- 100 (pasta); Revivid LCC Hemp Tincture 500mg (22:1 CBD/ THC (gotas) - 30 mL"(idem) ${ }^{4}$.

Caso o paciente usuário de derivados de maconha necessite de outro medicamento deveria ingressar com um pedido de autorização individual perante a autarquia. Assim, observa-se que a referida portaria trouxe uma grande possibilidade de acesso ao medicamento aos pacientes, estando superada muitas (mas não todas) das antigas dificuldades burocráticas, focando a luta pelo direito ao CBD medicinal na questão do direito ao acesso aos medicamentos, obstáculo que se dá devido ao alto preço dos mesmos. Este novo foco se dá em virtude dos altos custos da importação do referido medicamento inacessível para boa parte da população brasileira devido a seu valor de importação.

Com o fito de assegurar o direito ao acesso a tais medicamentos, cujos obstáculos, agora não mais plenamente impeditiva por parte da ANVISA em termos jurídico-burocrático,

4 Neste sentido, para retomar o contexto ver a narrativa de Oliveira \& Ribeiro (2017) 
mas sim em relação ao custo do mesmo que, por não ser produzido no Brasil, tinha um alto valor de importação que o tornava inacessível à maioria dos pacientes no Estado, foi planejada uma nova possibilidade de judicialização. A ferramenta seria uma Ação Civil Pública com o fito de garantir o fornecimento de medicamentos por parte do poder público.

Para garantir o acesso via Sistema Único de Saúde, foi dado entrada por parte do Ministério Público Federal da Paraíba - MPF-PB na Ação Civil Pública (ACP) $\mathrm{n}^{\circ}$ 080227183.2015.4.05.8200 em face da União e do Estado da Paraíba.

Anteriormente o MPF-PB já havia atuado no sentido de garantir o direito dos pacientes que necessitassem de medicamentos à base de canabidiol, tendo atuado extrajudicialmente através de um procedimento preparatório e judicialmente através de uma Ação Civil Pública que visava à autorização para importação de remédios a base de CBD. Assim, tendo em vista a necessidade de se continuar os trabalhos do MPF após a ACP responsável pela autorização de importação por parte dos pacientes do Estado e da mudanças normativa da ANVISA, foi convertido o Procedimento Preparatório $N^{\circ}$ 1.24.000001421/2014-74, que deu origem a Ação Civil Pública n 080254314.2014.4.05.8200 que conseguiu a autorização judicial para a importação do CBD, garantindo o acesso aos 16 pacientes do Estado da Paraíba, em Inquérito Civil, pela Portaria n 96/2015 de 15 de abril de 2015, cujo objetivo, agora, era de obter o fornecimento de tal medicação para os pacientes superando os entraves futuros para realização do direito ao acesso ao CBD tentando superar os obstáculos ainda existentes após a emissão da portaria supracitada da ANVI-

SA (BRASIL, 2015). Neste sentido, após uma primeira Ação Civil Pública, que foi bem-sucedida, houve a necessidade de continuidade dos trabalhos do MPF por via da judicialização de uma nova Ação Civil Pública. Será esta segunda ação cuja narrativa traremos abaixo.

Assim, destacamos neste trabalho três reuniões após a decisão judicial da Justiça Federal da Paraíba que garantiu o direito a importação dos medicamentos pela ANVISA e antes da conversão do Procedimento Preparatório em Inquérito Civil Público. Elas tinham como objetivo debater os efeitos da decisão no âmbito da Ação Civil Pública n 0802543-14.2014.4.05.8200 e os futuros caminhos após a autorização da mesma, até a estruturação do outro eixo de atuação que seria a obtenção dos medicamentos via SUS e a articulação para uma futura produção dos mesmos em âmbito nacional.

A primeira realizada aos onze dias do mês de setembro do ano de dois mil e quatorze (11/09/2014), logo após a decisão liminar. A reunião mostrou que a liminar que concedeu a autorização judicial seria apenas a primeira batalha a ser vencida para a realização plena do direito à saúde dos pacientes do CBD medicinal. A liminar que concedeu a autorização judicial para a importação dos medicamentos à base de CBD, que havia tido o seu ponto forte de ter superado os requisitos irrealizáveis impostos pela ANVISA para a importação, não havia superado os problemas que agora se iniciavam com a fase pós-autorização que seria a importação e o acesso à mesma. Observa-se que estaria havendo dificuldades com o processo de importação dos referidos medicamentos, tanto pelos pacientes que haviam conseguido a autorização judicial, quanto os que, apesar da burocracia, haviam conseguido a 
autorização diretamente da ANVISA (lembrando que a reclassificação data de 6 de maio de 2015).

Neste sentido relatam os pais, em declaração anexa aos autos, que, de posse da decisão, ao tentarem importar os medicamentos constataram que, devido a problemas referentes ao desembaraço aduaneiro, a obtenção do produto estaria sendo dificultada pela Receita Federal do Brasil no aeroporto de Viracopos em Campinas-SP. Informa-se, inclusive, que várias pessoas autorizadas, sejam judicialmente, sejam administrativamente, a importar o medicamento, estariam enfrentando essa mesma dificuldade (BRASIL, 2017 p.568). Apesar da autorização judicial emanada da ACP e da posterior reclassificação por parte da ANVISA vemos que, mesmo com a regulamentação/legalização que legitimou a importação, os obstáculos burocráticos ainda se faziam presentes.

A Receita Federal estaria exigindo a presença dos responsáveis pessoalmente ou a contratação de um despachante particular para tanto. Deste modo, vemos que para além da proibição de importação que havia sido derrubada, restavam outros obstáculos burocráticos. Sendo assim fica óbvio que se torna insustentável financeiramente para os pais tal procedimento, bem como, converte-se em uma verdadeira frustração as expectativas de efetividade dos bens jurídicos defendidos na ação que conseguiu a liminar de autorização.

Na reunião o representante da receita, esclareceu que, apesar de ter havido a autorização e os responsáveis podem importar os produtos, os trâmites legais aduaneiros deveriam ser respeitados, destacando que nestes trâmites a receita é a última a se posicionar, sendo exatamente a ANVISA a pri- meira a se pronunciar no ato do desembaraço, sendo este ato intitulado "anuência" (BRASIL, 2015 p.570).

Fato que foi interpretado pelo procurador como, em tese, desobediência à ordem judicial, mas, segundo o representante da receita, acredita-se que tais dificuldades devem ser resultantes de serem ainda os primeiros momentos de execução da importação5. Outro fato pontuado pelo procurador foi a falta de proporcionalidade de se exigir que, em um país das dimensões que tem o Brasil, o desembaraço aduaneiro tenha de ser feito pessoalmente nos aeroportos encarregados da recepção das mercadorias em remessa expressa que são: Viracopos, Galeão e Guarulhos ${ }^{6}$.

Foi deliberado naquela reunião que seria enviado cópia da decisão judicial liminar de autorização de importação junto com um depoimento ao funcionário da ANVISA junto ao aeroporto de forma que o mesmo se abstenha de impedir o desembaraço dos medicamentos (BRASIL, 2015).

Também se deliberou sobre a situação econômica e o alto valor da medicação que tornava inviável pra muitos pais arcarem com estaria caray pontuou que diência à ordem judicial emanada em sede de liminar na ACP O representante da Receita seguiu explicando os procedimentos de importação por correio oficial e por encomenda expressa, sendo nesta última incidente uma taxação fixa. Colocou que o desembaraço através de despachante é prática regulamentada pela Receita, e que um trabalho de sensibilização frente aos servidores dos postos que recebem os produtos pode facilitar a fluidez do procedimento de importação que para a entidade, e relativamente novo diante das circunstâncias. Relatou que acredita que essas dificuldades devem estar surgindo por conta desse primeiro momento de execução da importação do produto" (BRASIL. 2015, p. 570).

6 "Dr. Godoy, tomando a palavra, pontuou que é irrazoável que, em um país continental como o nosso, um cidadão, para conseguir desembaraçar um medicamento, tenha de se deslocar, como no presente caso, de João Pessoa-PB até Campinas-SP. Dessa forma, como foi informado pelo representante da Receita que esse procedimento aduaneiro passou a ser implementado no Brasil a partir de 1999, fica caracterizada uma má prestação de serviço público pela concentração do desembaraço nessas localidades, distantes das demais regiões do país, passível de investigação pelo Ministério Público Federal, notadamente pelos membros que atuam em matérias vinculadas à la Câmara de Coordenação e Revisão. A questão da obrigatoriedade do despachante para esses procedimentos também seria passível dessa mesma atenção, já que impossibilita até o deslocamento do cidadão para o local do desembaraço, ou mesmo de procurador idôneo, de forma a obter a mercadoria" (BRASIL. 2015, p. 571). 
os custos do tratamento de seus filhos. As soluções pensadas foram: a) lutar pela fabricação, em território nacional, dos referidos medicamentos, ou b) ações judiciais que visassem o custeio dos mesmos pelo Sistema Único de Saúde - SUS7. Tal tema perpassará as próximas reuniões, conforme se verá a seguir.

Uma destas reuniões aos sete dias do mês de novembro do ano de dois mil e catorze, oportunidade em que superado os primeiros entraves burocráticos por parte da $\mathrm{AN}$ VISA, seria necessário para garantir o direito à saúde dos pacientes que se conseguisse o fornecimento dos referidos medicamentos via SUS, haja vista os encargos financeiros elevados para se conseguir tal medicamento. Foi destacada a importância de se conseguir um atestado que, fornecido por profissional habilitado, pudesse descrever as melhoras no quadro clínico dos pacientes de forma a evidenciar a necessidade de fornecimento. Aqui vemos a força do discurso médico que entra como uma importante ferramenta para a construção deste direito, sendo, como base em Foucault (1999), que afirmamos haver uma reestruturação a partir do agregado médico-jurídico das relações de poder capazes de oposição às estruturas postas. $O$ discurso médico entra como importante ferramenta de convencimento dada a natureza de saber-poder das estruturas discursivas da medicina contemporânea.

Nesta reunião foi debatida a questão de que existem diferenças nas fórmulas dos diversos laboratórios e que uma pequena modi-

\footnotetext{
7 "Dr. Godoy, sobre o tema, externou sua preocupação em intentar qualquer ação para obrigar o fornecimento, via SUS, de medicação ainda em fase experimental. Um caminho interessante, destacou, seria buscar a liberação do registro do medicamento em solo nacional, que teria como consequência direta a queda do preço do produto com a fabricação local. Outra alternativa seria lançar pedidos pontuais para que as pessoas já beneficiadas com a medida liminar, e com o tratamento em curso, possam obter o fornecimento do Cannabidio pelo SUS judicialmente" (BRASIL. 2015, p. 571)
}

ficação na composição de um remédio para o outro poderia modificar a reação dos pacientes, pois cada pessoa teria progresso no tratamento de forma diferente dependendo do extrato, forma de administração e laboratório (BRASIL, 2015).

Outra reunião ocorreu aos vinte e nove do mês de janeiro do ano de dois mil e quinze (29/01/2015), às 15h, na Procuradoria da República na Paraíba. Nesta reunião foi anunciada a criação da Associação Brasileira de Pacientes de Cannabis Medicinal - AMA+ME "associação que trabalha em prol do acesso dos pacientes à substância, em face do preconceito de alguns médicos com o canabidiol e o próprio desconhecimento que há sobre o medicamento em razão da proibição de importação que havia até pouco tempo" (BRASIL, 2015 p.636). O preconceito da classe médica é um tema que ainda persiste mesmo após a reclassificação, sendo difícil conseguir os laudos médicos mesmo após a reclassificação do CBD pela ANVISA. A atuação extrajudicial tem como marco a integração de vários atores neste cenário, no qual se destacam, movimentos sociais, entidades produtoras de conhecimento e de práticas em saúde e etc. Foi abordada a questão de uma possível parceria com a Universidade Federal da Paraíba de forma a viabilizar pesquisas sobre o CBD, pois o mesmo ainda é muito pouco conhecido em termos de pesquisas científicas no Brasil. Ao final, ficou deliberado que: "o MPF vai celebrar com a Secretaria de Saúde do Estado da Paraíba Termo de Ajustamento de Conduta para que a mesma realize a compra e posterior distribuição gratuita do canabidiol para os pacientes beneficiados com a medida liminar no respectivo processo judicial" (idem).

Tal termo foi celebrado aos 13 dias de feve- 
reiro de 2015 entre o MPF e a secretaria Estadual de Saúde do Estado da Paraíba, onde o Governo do Estado se comprometeu a fornecer às 16 (dezesseis) crianças e jovens constantes e que seriam pacientes no Estado, o medicamento à base de Canabidiol necessário ao tratamento de cada uma delas, por tempo indeterminado. O referido título tem eficácia de título executivo extra judicial (BRASIL, 2015 p.645).

Um pouco antes da conversão do PP em ICP, para a viabilização de uma nova Ação Civil Pública, cujo objetivo seria o fornecimento dos medicamentos via SUS, houve outra reunião em 09/04/2015 na Reitoria da UFPB com a presença da Reitora da UFPB, de representantes do Ministério Público, de representantes da comissão da Comissão de Direito Sanitário e Biodireito da OAB, da Anvisa e a Associação de Pacientes de Cannabis Medicinal, cujo objetivo era traçar as estratégias de parcerias para viabilização de pesquisas científicas sobre os produtos à base de canabidiol para uso medicinal e ações institucionais para viabilizar o seu acesso. Desta forma o encontro visava,

\section{[...] firmar um convênio entre as entida- des e a UFPB para dar início às pesquisas de análise de amostras dos medicamen- tos que são importados para o tratamen- to da Eplepsia Refratária entre outras do- enças que podem ser tratadas com o uso de óleos e extratos de Cannabis (BRASIL, 2015).}

Entre os temas debatidos, segundo o portal oficial da UFPB, estavam:

[...] pesquisas com os medicamentos que já conseguem entrar no país, importados com autorização judicial. Controle de qualidade, efeitos colaterais, toxicidade, variação de níveis da droga entre diferentes fabricantes, interação com outros medicamentos e acompanhamento psicológico e médico de pacientes usuários, estavam entre os pontos principais discutidos, para que pesquisas sejam iniciadas pela
UFPB com o acompanhamento da Anvisa, do Ministério Público e da OAB (idem).

Sobre o encontro a reitora da UFPB, se posicionou:

\begin{abstract}
Vamos criar uma equipe de pesquisa para acompanhar e dar maior segurança aos pacientes e seus familiares. O Instituto de Fármacos e Medicamentos da UFPB, antigo LTF, vai dar início aos trabalhos com uma equipe multidisciplinar de pesquisadores para coletarmos os primeiros dados e para o acompanhamento dos pacientes e familiares (idem).
\end{abstract}

Júlio Américo, um dos familiares que luta pelo direito ao uso da maconha medicinal, e, que posteriormente, seria fundador e presidente da Liga Canábica da Paraíba, declarou, segundo o portal oficial da referida instituição, que a reunião foi proveitosa e que "Essas pesquisas não vão beneficiar apenas nossos filhos, mas todos que precisam do uso da maconha medicinal. Esperamos que no futuro possamos regulamentar esse uso" (idem).

Já após a conversão do Procedimento Preparatório em Inquérito Civil, ocorreu uma reunião aos quatro dias de maio de 2015 realizada na Sala das Comissões do prédio sede da OAB, Seccional da Paraíba, para tratar de encaminhamentos relativos ao Termo de Cooperação Técnica a ser firmado com a UFPB, MPF, ANVISA, Associação de pacientes, OAB e outros órgãos. Nestes termos foi abordada a necessidade de se deslocar o fluxo das importações para a Paraíba de forma a baratear o custo da exportação. Quanto à indagação dos representantes dos pacientes sobre como seria possível obter o CBD para efetivar as pesquisas no âmbito da UFPB foi sugerido por parte do representante da ANVISA a confecção de projetos temáticos, de forma a obter financiamentos. Foi debatido também, no âmbito desta reunião, a criação de um time nas vertentes jurídicas, cientí- 
ficas e médicas (BRASIL, 2015, p.658). Decidiu-se, no âmbito desta reunião, que seria criado um Conselho de Gestão e um Grupo Executivo. Sobre o projeto no âmbito da UFPB o mesmo, segundo a professora responsável, envolveria a obtenção "de matéria-prima, o controle de qualidade (controle estatístico sobre a qualidade de vida dos pacientes e efeitos neurológicos, com o auxílio, por óbvio, de médicos neurologistas que se dispuseram a contribuir) e a sinterização do CBD" (BRASIL, 2015 p.658). Outro projeto sugerido foi a documentação em mídia da história dos pacientes para "registrar a história do grupo e reforçar a conscientização sobre o tema" (BRASIL, 2015 p.658).

Na Reunião 24 de julho de 2015 no auditório da Procuradoria da República no Estado da Paraíba, com a presença dos Professores que compõem a equipe do Instituto de Pesquisa em Fármacos e Medicamentos (IPEFARM) da UFPB com o objetivo de debater a pesquisa sobre o extrato de Canabidiol. $O$ encontro buscou realizar uma "descrição detida, por conta dos pesquisadores, dos trabalhos a serem executados pela equipe dentro da proposta que resultaram na assinatura de Termo de Cooperação Técnica entre a UFPB, ANVISA, OAB/PB, MPF, Associação de pais e pacientes e outros órgãos" (BRASIL, 2015 p.729). Foi destacado, por um dos pesquisadores, que os estratos de CBD importados pelos pacientes seriam objeto de análise como matéria prima nas pesquisas a verificar o teor do princípio ativo anunciado (CBD). "O objetivo da pesquisa, nessa linha, seria qualificar esses fornecedores para obter registro junto à ANVISA, até agora inexistente" (BRASIL, 2015 p.729). Quanto à necessidade de se realizarem pesquisas clínicas de acompanhamento dos pacientes, foi destacado que a licença junto à $A N$ -
VISA só ocorreria após a realização destas pesquisas clínicas.

O Procurador Regional dos Direitos do Cidadão demonstrou a intenção do MPF de apoiar a pesquisa, para que em médio prazo possa-se desenvolver a produção da substância no âmbito da Universidade Federal da Paraíba, de forma a, com a produção local capitaneada pela UFPB, possa-se diminuir os custos e dar continuidade ao processo de conhecimento dos produtos aqui produzidos. Desta forma o Procurador Regional dos Direitos do Cidadão destacou a irrazoabilidade de importar a altíssimos custos um produto de baixa tecnologia que poderia ser produzido no Brasil. Esta preocupação apresentada pelo procurador é fundamental e atinge o cerne da luta pelo direito ao acesso à maconha medicinal no Brasil: a necessidade de regulamentação do plantio e da produção de remédios no Brasil. Mostra-se totalmente fora de qualquer senso de razoabilidade a importação de um produto que pode ser cultivado e produzido aqui no Brasil, barateando seu custo. Em resposta, um dos pesquisadores do IPeFarM informou que:

[...] compreende a pressa dos pais e responsáveis, mas que o trabalho científico não caminha nessa mesma velocidade. Para adentrar nessa, etapa da produção, seria necessário um trabalho mais voltado à agronomia, com a participação de professores dessa área, para analisar o solo, a época do plantio e cultivo e as variedades da Cannabis propícias à obtenção do CBD (BRASIL, 2015 p.730).

Neste ponto o Procurador Regional dos Direitos do Cidadão, segundo a memória de reunião em comento:

[...] solicitou que o IPEFARM ${ }^{8}$ ajudasse a contatar outros grupos de professores (no Campus de Areia, inclusive) dentro da proposta da produção autóctone, para uma via mais econômica em dire-

8 Instituto de Pesquisa em Fármacos e Medicamentos

DIREITOS HUMANOS E O ACESSO À MACONHA MEDICINAL

PARA FORNECIMENTO GRATUITO DE MEDICAMENTOS

PELO SUS: um estudo de caso da Ação Civil Pública

n० 0802271-83.2015.4.05.8200 
ção aos objetivos da pesquisa. Outros grupos poderiam, até com o auxílio de entidades privadas, realizar estudos sobre o número de pessoas portadoras de epilepsia refrataria no país (que não é baixo), de forma a atrair a atenção e o investimento do Ministério da Saúde para a importância da pesquisa, proposta que foi recebida positivamente pela equipe (BRASIL, 2015 p.732).

A Proposta do IPeFarM para o Convênio do Canabidiol envolvendo várias entidades, entre as quais UFPB, ANVISA, OAB/PB, MPF, Associação de pais e pacientes e outros órgãos foi encaminhada nos seguintes termos:

OBJETO: Desenvolver uma forma farmacêutica contendo o derivado vegetal rico em canabidiol como matéria prima, visando o registro do produto na ANVISA para produção e disponibilização no Sistema Único de Saúde.

OBRIGAÇÃO DO IPeFarM: 1. Elaborar o projeto científico, tecnológico e de produção de uma forma farmacêutica contendo a matéria prima ricaem canabidiol. 2. Desenvolver e validar tecnologia analítica para análise do canabidiol na matéria prima e produto acabado; 3. Qualificar o(s) fornecedor(es) da matéria prima rica em canabidiol; 4. Realizar os estudos farmacológicos e toxicológicos não clínicos para confirmar as atividades farmacológicas principal e secundárias, bem como a segurança de uso dessa matéria prima pelo ser humano; 5. Desenvolver a tecnologia de produção do biolote da forma farmacêutica para os estudos clínicos; 6. Elaboração do Protocolo de Estudos Clínicos e solicitar autorização da ANVISA para realização dos estudos clínicos com os pacientes; 7. Realizar os estudos clínicos do produto validado tecnologicamente com os voluntários saudáveis e pacientes conforme preconiza as boas práticas de estudos clínicos. 8. Solicitar o registro do produto na ANVISA para comercialização (BRASIL, 2015 p.732).

Estas reuniões, as diligências obtidas a par- tir delas e a atuação como um todo da Procuradoria Federal dos Direitos do Cidadão deram embasamento para a propositura da ação objeto deste estudo. Vemos uma intensa atuação extrajudicial da Procuradoria Federal dos Direitos do Cidadão na luta pelo direito ao acesso à maconha medicinal, sendo um importante aliado dos movimentos sociais no Estado da Paraíba na luta pelo acesso. Boa parte desta atuação e dos dados obtidos com parceiros como a UFPB, compuseram um corpus discursivo importante que vai ajudar na formação de um discurso jurídico expresso na ACP que terá um grande potencial de enfrentamento. Neste contexto, de fortalecimento dos trabalhos do MPF, é que se deu a entrada da Ação Civil Pública, embasada pelo Inquérito Civil em comento, assinada aos 15 dias do mês de junho, que deu origem ao processo número 0802271-83.2015.4.05.8200, com o objetivo de conceder o fornecimento do CBD pelo SUS, nos seguintes termos:

Em face de tudo quanto acima foi exposto, o MINISTÉRIO PUBLICO FEDERAL requer:

a) a concessão de antecipação de tutela nos termos formulados acima (item "7", letras "a", "b" e "c");

b) a citação dos demandados, nos endereços mencionados no início da presente peça, para, querendo, responder aos termos da presente ação, sob pena de revelia;

c) provar o alegado por todos os meios em Direito admitidos, especialmente, juntada posterior de documentos, realização de perícias médicas e oitiva de testemunhas, tudo desde logo requerido; d) por fim, a procedência do pedido, ordenando-se à UNIÃO e ao ESTADO DA PARAÍBA:

d.1) o fornecimento gratuito, aos substituídos enumerados no item anterior (pacientes medicinais) do medicamento "Canabidiol" suficiente para o tratamento de cada uma delas, por tempo indeterminado, em periodicidade mensal, nas 
quantidades de frascos, concentrações e dosagens necessárias, conforme lista detalhada em anexo, contendo, inclusive, sugestão de custos;

d.2) que modifiquem, a pedido dos responsáveis, no curso do fornecimento, a quantidade, a apresentação (do tipo de extrato pasta ou óleo) e o fabricante da substância, de acordo com a resposta ao tratamento e a eventual alteração na dosagem prescrita pelo médico que acompanhe a necessidade específica de cada paciente;

d.3) a realização de todos os contatos com os fornecedores para a aquisição dos fármacos, bem como todo o processo de compra, importação, frete e desembaraçamento dos medicamentos (inclusive as providências para a liberação perante a aduana brasileira, utilizando-se, para tanto, das determinações na sentença da ACP Nº. 0802543-14.2014.4.05.8200, 1a Vara Federal do Estado da Paraíba), bem como a estocagem e distribuição da substância, desde que obedeça à periodicidade mensal necessária para o cumprimento dos itens "a" e "b" acima;

d.4) a apresentação, à parte autora, no prazo de 30 (trinta) dias contados do provimento jurisdicional, de cronograma completo de aquisição, estocagem e fornecimento da medicação, válido por, no mínimo, 2 (dois) anos que, ao final desse período, será substituído por outro cronograma, para idêntico período subsequente, e assim por diante, sendo que sua não apresentação não desobrigará os entes de iniciar ou continuar o fornecimento do fármaco;

d.5) a aplicação de multa diária na ordem de $\mathrm{R} \$ 10.000,00$ (dez mil reais) para cada promovido, em razão de eventual descumprimento a quaisquer das determinações acima, a ser revertida ao Fundo de Defesa dos Direitos Difusos.

e) a dispensa do pagamento de custas, emolumentos e outros encargos, na forma do que dispõe o art. 18 da Lei Federal n 7.347/1985, e no artigo 87, do Código de Defesa do Consumidor;

f) por fim, dá-se à causa, para efeitos fiscais, o valor de $\mathrm{R} \$ 10.000,00$ (dez mil reais) (BRASIL, 2015 p.698).

A decisão da Justiça Federal da Paraíba, no presente feito, veio a conceder o direito ao fornecimento pelo SUS, em decisão proferida aos 08 dias de julho de 2015, nos seguintes termos:

ISSO POSTO, DEFIRO o pedido de antecipação dos efeitos da tutela, para determinar à UNIÃO e ESTADO DA PARAÍBA que forneçam aos substituídos elencados na tabela supra o medicamento canabidiol, conforme divisão de atribuições administrativas e de custeio discriminadas nesta decisão (BRASIL, 2015 p.711).

Assim, como começa a se delinear, no âmbito jurídico, uma certa preocupação com a efetividade dos direitos humanos dos pacientes do CBD medicinal. Observamos isto nas duas ações bem sucedidas para a consecução do direito ao uso do CBD medicinal no Estado, uma delas para autorizar a importação e a outra para conseguir o custeio do mesmo pelo Sistema Único de Saúde.

Observamos também que, apesar dos avanços na desconstrução do paradigma proibicionista em relação à maconha no que diz respeito ao seu uso medicinal, ainda há forte preconceito aos demais usos pois, se mantém bastante enraizado em nossa cultura jurídica, que a Liminar que concedeu tal direito, foi em âmbito de Segunda Instância revogada, pela Quarta Turma do Tribunal Regional Federal da $5^{a}$ Região que seguiu o voto do relator no agravo interposto pela União, sob os argumentos de que: não existe estudo definitivo que comprove a eficácia alegada no tratamento de crises epiléticas; o SUS já dispõe de medicamentos anticonvulsionantes que são distribuídos gratuitamente pelo Estado (lista Relação Nacional de Medicamentos Essenciais - RENAME), devendo se dar preferência a estes medicamentos por uma questão de isonomia e da legalidade. A decisão que cassou 
a liminar utiliza em sua argumentação o mesmo artigo de Roberto Barroso (2007), intitulado "Da falta de efetividade à jurisdicionalização excessiva: direito à saúde, fornecimento gratuito de medicamentos e parâmetros para a atuação judicial", citado na decisão de primeira instância que concedeu tal liminar de fornecimento gratuito. Assim, observa-se a reversibilidade do discurso jurídico frente aos saberes médicos hegemônicos e a dificuldade da desconstrução dos pressupostos fundamentais dos regimes de verdades que mantém as estruturas proibicionistas. Esta reversibilidade do discurso jurídico já foi apontada por Sanchez Rúbio (2006) e Salo de Carvalho (2013), que com seus estudos nos permite ver a possibilidade de como o discurso jurídico, ao incorporar categorias dos direitos humanos, o faz de forma reversível, podendo, o direito ser aplicado de várias formas possíveis, inclusive de forma antagônica.

A primeira Ação Civil Pública, que reclassificou o CBD se encontra em um momento de emergência dos discursos sobre a legalização da maconha medicinal, influenciado pela visibilidade do documentário "llegal" e da campanha que o seguiu de mobilização de famílias que dependiam da maconha medicinal, o certo é que a referida ação foi intentada em outros estados e depois de várias derrotas judiciais a ANVISA se viu pressionada a reclassificar o CBD para fins terapêuticos (OLIVEIRA \& RIBEIRO, 2017). No âmbito da segunda ação de custeio, inovase também ao incluir um medicamento que não estava incluído na Relação Nacional de Medicamentos Essenciais (RENAME), mas que foi concedida em virtude da necessidade dos pacientes e da comprovação da eficácia do medicamento, aliado logicamente às mudanças de perspectivas dentro do âm- bito da ANVISA (a reclassificação do CBD) e do CFM (a aprovação do uso compassivo do CBD para pacientes refratários a medicamentos tradicionais). Entretanto não se pode observar tal aceitabilidade como uma marcha linear, mas sim, como embates, pois estão sujeitas a avanços, como os vistos até este momento, mas também a retrocessos. Neste sentido, no âmbito da segunda instância, tal fornecimento gratuito pelo SUS foi caçado por decisão, também em caráter liminar, sob argumento de que não havia comprovação do tratamento à base de CBD pelas ciências médicas, contrariando toda linha argumentativa, laudos e estudos apontados pelo MPF, mostrando os efeitos do poder político na estruturação do discurso médico como um elemento de pressão extra-discursivo com muito mais peso no âmbito do judiciário, do que os elementos intra-discursivos dos saberes médicos.

Vemos então como a luta pela maconha medicinal constitui-se como um importante contradiscurso (FOUCAULT, 1999; SPARGO, 2017), que utilizando o saber médico contra o discurso médico hegemônico pode produzir importantes fissuras ao regime de verdade médico-jurídico proibicionista. Mas, é importante que observemos a reversibilidade do discurso de poder, para tentar fugir da análise da linearidade e gradual conquista de direitos humanos para observa-los como uma luta sujeita a vitórias e derrotas. Tal se expressa pela decisão que retirou os efeitos da liminar anteriormente conquistada.

\section{Uma conclusão a se construir: a tutela da maconha medicinal entre a judicialização de medicamentos e a autoprodução.}

As ações que visam ao fornecimento gratuito da maconha medicinal, ainda se pro- 
liferam no ordenamento jurídico brasileiro, mas se encontram sujeitas à insegurança jurídica, pois não há garantia alguma de que terão os direitos materiais à saúde de fato efetivados. O argumento da reserva do possível é uma construção discursiva importante para bloquear a efetivação deste direito. Argumenta-se que frente a impossibilidade do Estado cobrir toda a demanda por saúde dos cidadãos, haveria limites, uma reserva do possível orçamentário que impossibilitaria o fornecimento de medicamentos que não estariam previstos em lista elaborada pelo poder público. Como os derivados de maconha não se encontram nesta lista, este é um argumento retórico para criar um obstáculo ao direito ao acesso. Assim, frente à insegurança jurídica e a decisões conflitantes os pacientes se encontram em situação extremamente vulneráveis. Com o registro de medicamentos à base de cannabis a serem produzidos no Brasil as decisões podem vir a tomar forma mais favoráveis aos pacientes haja vista a menor oneração do SUS. De qualquer forma, "a vida não espera" como destaca o documentário "llegal". E neste sentido quem mais sofre são os pacientes.

Com vista a esta realidade as judicializações começaram a tomar nova estratégia, qual seja, a busca de Habeas Corpus para a resguardar o direito a produção individual de óleos fitoterápicos e ações coletivas de autorização para o cultivo e produção de remédios por parte de associações, tendo como caso emblemático a ação da Associação Brasileira de Apoio Cannabis Esperança - ABRACE, ONG paraibana que foi a primeira associação a vencer uma ação coletiva e ter sua plantação de maconha legalizada no Brasil. Estas decisões inéditas e pioneiras fazem com que a esperança dos pacientes se- jam renovadas, mesmo em um contexto de descaso. As judicalizações de habeas corpus e de autorizações para o cultivo associativo constituem um importante passo na luta pelo acesso à maconha medicinal.

Vemos a possibilidade de regulação do auto cultivo, do cultivo associativo, bem como, a inclusão de remédios à base de maconha na lista RENAME em paralelo com a produção nacional de remédios serão pontos importantes na luta pelo acesso. Estas questões envolvem providencias no âmbito dos poderes legislativos e executivos. Estas providências poderiam superar a insegurança jurídica presente no processo de judicialização do direito ao acesso à maconha medicinal nas suas várias formas, seja para o fornecimento gratuito de remédios, seja na autorização para a autoprodução fitoterápica, dando densidade ao direito à saúde. A vida dos pacientes não pode estar à mercê das flutuações de opiniões dos órgãos julgadores e demandam políticas públicas e alterações de bases legais e regulamentares de modo a democratizar o acesso a remédios à base de maconha.

Com isto encerramos a análise desta ação emblemática de modo a contextualizar a realidade da judicialização do direito à saúde de pacientes de maconha medicinal. As ações de fornecimento gratuito pelo SUS se constituem uma importante ferramenta de efetivação do direito ao acesso à maconha medicinal. Mas se limitam em eficácia graças à instabilidade ocasionada por decisões conflitantes, que se apoiam no argumento da falta de recursos. Este pode ser um motivo para a recente guinada na busca do auto cultivo, hipótese que extrapola o objetivo deste artigo, mas que merece exploração por parte de outras pesquisas jurídicas. Importante é que o fornecimento gratuito pelo 
SUS ainda continua sendo uma ferramenta utilizada no processo de judicialização do direito à maconha medicinal e neste sentido uma análise crítica dos percalços que a opção por esta forma de demanda judicial é importante por mostrar a necessidade de uma maior conscientização por parte dos órgãos regulamentares na tentativa de baratear este fornecimento a partir da produção de remédios locais e do incentivo a produção por parte de associações que já possuem a expertise de produção fitoterápica.

O universo da judicialização do direito à maconha medicinal constitui-se como uma área que merece importante destaque por parte dos saberes médicos e jurídicos, pois lidam com a vida de pacientes em estado de vulnerabilidade. Em paralelo ao processo de judicialização a atuação política de grupos de pacientes, familiares e militantes produziram significativo impacto na luta pelo direito à saúde e pela superação das restrições legais ao uso da maconha medicinal. Na Paraíba a Liga Paraibana em Defesa da Cannabis Medicinal - Liga Canábica-PB, junto com a ABRACE constituem importantes associações na luta política pelo acesso à maconha medicinal. Estas associações assumiram o protagonismo da luta e enfrentaram o saber-poder médico-jurídico produzindo grandes modificações que tornaram a Paraíba um importante Estado na luta pelo direito à maconha medicinal. A partir de parcerias importantes como a da Procuradoria Federal dos Direitos do Cidadão - que patrocinou duas ACP como parte ativa e atuou em defesa da maconha medicinal como fiscal da lei, na ação proposta pela ABRACE, - e da Universidade Federal da Paraíba - que possui importantes projetos de extensão e pesquisa que visam produzir conhecimentos médicos sérios sobre a maconha medicinal coordenados pela Dra. Katy Lísias G. D. de Albuquerque - esta pode obter importantes vitórias em uma narrativa que se constrói a cada dia, pelo protagonismo dos pacientes, familiares e associações com importantes apoios institucionais e de outros movimentos sociais na área de drogas e direitos humanos.

\section{Referências}

ARAÚJO, Tarso (2014). ILEGAL. Documentário. 90 min. Disponível em: https://www.youtube.com/watch?v=I072TOenO4. Acessado em: 04/06/2015.

BARROSO, Luís Roberto (2007). Da falta de efetividade à judicialização excessiva: direito à saúde, fornecimento gratuito de medicamentos e parâmetros para a atuação judicial. Revista de Direito da Procuradoria Geral do Estado do Rio de Janeiro. Encontrado em: https://www.conjur.com.br/dl/estudobarroso.pdf. Acesso em: 14/05/2016.

BRASIL (2016). Resolução da Diretoria Colegiada - RDC N 66 de 18 de março de 2016. Dispõe sobre a atualização do Anexo I (Listas de Substâncias Entorpecentes, Psicotrópicas, Precursoras e Outras sob Controle Especial) da Portaria SVS/MS n 344, de 12 de maio de 1998, e dá outras providências. Disponível em: < http:// pesquisa.in.gov.br/imprensa/jsp/visualiza/index.jsp?jornal=1\&pagina $=28 \&$ data $=21 / 03 / 2016 \mathrm{br}>$. Acesso em: 04 abr. 2015.

BRASIL (2014). Ministério Público Federal. Procedimento Preparatório n 1.24.000.001421/2014-74. PFDC. Saúde. Canabidiol. Acesso à medicação. Reclassificação junto à ANVISA. Disponibilidade pelo SUS. Partes: representante: Sheila e outros; representados: ANVISA. Autuado 09/07/2014.

BRASIL (2014). Justiça Federal. Ação Civil Pública n 0802543-14.2014.4.05.8200, ajuizada em 31 de juIho de 2014 (1 $1^{\text {a }}$ Vara Federal). In: BRASIL. Ministério Público Federal. 192 Procedimento Preparatório $n$ 1.24.000.001421/2014-74. PFDC. Saúde. Canabidiol. Acesso à medicação. Reclassificação junto à ANVISA. Disponibilidade pelo SUS. Partes: representante: Sheila e outros; representados: ANVISA. Autuado 09/07/2014. 
BRASIL (2015). Justiça Federal. Ação Civil Pública n 0802271-83.2015.4.05.8200, ajuizada em ajuizada em 15 de junho de 2015 (3 $3^{a}$ Vara Federal). In: BRASIL. Ministério Público Federal. Inquérito Civil Público n 1.24.000.001421/2014-74. PFDC. Saúde. Canabidiol. Requer intervenção da PRDC, no sentido de garantir o acesso ao cannabidiol (CBD); intervir junto à ANVISA para que o tema seja tratado com urgência e relevancia; assegurar o custeio do tratamento (SUS) e solicita ao CFM que emita um documento orientando os médicos sobre o uso do cannabidiol. Partes: representante: Sheila e outros; representados: ANVISA e outros. Convertido em 15/04/2015.

BRASIL (2015). Ministério Público Federal. Inquérito Civil Público n 1.24.000.001421/2014-74. PFDC. Saúde. Canabidiol. Requer intervenção da PRDC, no sentido de garantir o acesso ao cannabidiol (CBD); intervir junto à ANVISA para que o tema seja tratado com urgência e relevancia; assegurar o custeio do tratamento (SUS) e solicita ao CFM que emita um documento orientando os médicos sobre o uso do cannabidiol. Partes: representante: Sheila e outros; representados: ANVISA e outros. Convertido em 15/04/2015.

BRASIL (2014). Universidade Federal da Paraíba UFPB. UFPB dará início às pesquisas para controle de qualidade dos medicamentos à base de maconha. João Pessoa. Encontrado em: http://www.ufpb.br/content/ufpb-dar\%C3\%A1-in\%C3\%ADcio-\%C3\%AOs-pesquisas-paracontrole-de-qualidade-dos-medicamentos-\%C3\%AO-base-de-maconha.

BRASIL (2014). Ministério Público Federal. Sai sentença de mérito em favor da importação do canabidiol por famílias paraibanas. Encontrado em: http://www. prpb.mpf.mp.br/news/sai-sentenca-de-merito-em-favor-da-importacao-docanabidiol-por-familias-paraibanas. Acessado em: 04/06/2014.

BRASIL (2017). Ministério da Justiça. Levantamento Nacional de Informações Penitenciárias Atualização Junho de 2016. Brasília.

BOITEUX, Luciana (2014). Drogas e cárcere: repressão às drogas, aumento da população penitenciária brasileira e alternativas. In: SHECARIA, Sergio Salomão (Org.). Drogas uma nova perspectiva. São Paulo: IBCCRIM.

BOITEUX, Luciana (2015). Brasil: reflexões críticas sobre uma política de drogas repressiva. In: Revista Sur: Revista internacional de Direitos Humanos, v.12, N. 21. CASTILHO, Ela Wiecko Volkmer de; et ali (org.) (2009). Série Pensando o Direito: Tráfico de Drogas e Consti- tuição. Faculdade Nacional de Direito da Universidade Federal do Rio de Janeiro/Universidade de Brasília: Rio de Janeiro/Brasília.

CARVALHO, Salo de (2013). Anti-manual de criminologia. São Paulo: Saraiva.

CARVALHO, Salo de (2013). A política criminal de drogas no Brasil: estudo criminológico e dogmático. 6 ed. São Paulo: Saraiva.

CARLOS, Juliana de Oliveira (2015). Política de drogas e encarceramento em São Paulo, Brasil. Reino Unido: Consórcio Internacional sobre Políticas de Drogas (IDPC). Encontrado em: https://dl.dropboxusercontent.com/u/64663568/library/IDPCbriefing-paper_Drug-policy-in-Brazil-2015_PORTUGUESE.pdf Acesso em: 16/10/2015

DELMANTO, Júlio (2013). Camaradas caretas: drogas e esquerda no Brasil após 1961. São Paulo: Faculdade de Filosofia, Letras e Ciências Humanas, Universidade de São Paulo. Dissertação de Mestrado em História Social.

FOUCAULT, Michel (1999). Em defesa da sociedade: curso no Collège de France (1975- 1976). São Paulo: Martins Fontes.

FOUCAULT, Michel (2009). A Verdade e as Formas Jurídicas. 3. ed. Rio de Janeiro: Nau.

FOUCAULT, Michel (2013). Vigiar e punir: nascimento da prisão. 36a ed. Petrópolis: Vozes.

FOUCAULT, Michel (2013). A ordem do discurso aula inaugural no College France pronunciada em 2 de dezembro de 1970.São Paulo: Edições Loyola.

FOUCAULT, Michel (2014). História da sexualidade 1: A vontade de saber. São Paulo: Paz e Terra.

FOUCAULT, Michel (2002). Os Anormais: Curso no College de France (1974-1975). São Paulo: Martins Fontes. JESUS, Maria Gorete Marques de (Org.) (2011). Prisão Provisória e Lei de Drogas: Um estudo sobre os flagrantes de tráfico de drogas na cidade de São Paulo. São Paulo: Núcleo de Estudo da Violência da USP.

MATTOS, Paulo E. Orlandi (2015). Modelos internacionais de regulamentação do uso medicinal da cannabis. In: Drogas no Brasil: entre a saúde e a justiça : proximidades e opiniões / Vilma Bokany (organizadora). - São Paulo: Editora Fundação Perseu Abramo.

OLIVEIRA, Lucas Lopes (2016). Discursos médicos e jurídicos sobre maconha no Brasil e na Paraíba: os contradiscursos no debate sobre as políticas de drogas à luz dos direitos humanos. (Dissertação de Mestrado). Programa de Pós-Graduação em Direitos Humanos, Cidadania e Políticas Públicas - PPGDH/UFPB. 
OLIVEIRA, Lucas Lopes; RIBEIRO, Luziana Ramalho (2017). Discursos Médicos e Jurídicos Sobre Maconha na Paraíba: a judicialização do direito ao acesso à maconha medicinal. Revista de Estudos Empíricos em Direito, v. 4, n. 2.

OLIVEIRA, Lucas Lopes; RIBEIRO, Luziana Ramalho (2016). Políticas públicas de drogas no Brasil e Direitos Humanos. Revista Interdisciplinar de Direitos Humanos, v. 4, n. 1, p. 139-159.

PAULINO, Fernando Oliveira; PINTO, Jeronimo Calorio (2013). Direito à comunicação, liberdade de expressão e marcha da maconha. Eptic online: revista electronica internacional de economia política da informaçao, da comuniçao e da cultura, v. 15, n. 3, p. 162-176.

RODRIGUES, Thiago (2008). Trafico, guerra e proibição. In: LABATE, Beatriz Caiuby e outros (Org.). Drogas e cultura: novas perspectivas. Salvador: EDUFABA.

RÚBIO, David Sánchez (2006). Reversibilidade do direito: os direitos humanos na tensão entre mercado, os seres humanos e a natureza. Revista de estudos criminais(22) porto alegre: notadez/ PPGC- Crim PUCRS/ ITEC.

RÚBIO, David Sánchez; FLORES, Joaquín Herrera; DE CARVALHO, Salo (2010). Direitos humanos e globalização. EDIPUCRS: Porto Alegre.

SALIH, Sara (2017). Judith Butler e a teoria queer. Belo Horizonte: Autêntica, Editora.

SPARGO, Tamsin (2017). Foucault e a teoria queer: seguido de Ágape e êxtase: orientações pós-seculares. Belo Horizonte: Autêntica (Argos, 2).

ZALUAR, Alba (2000). Para não dizer que não falei de samba: os enigmas da violência no Brasil. In: ZALUAR, A. História da vida privada no Brasil, Vol. III. Contrastes da intimidade contemporânea. São Paulo: Companhia das Letras.

Data de submissão: 21/09/2018

Data de aceite: 09/04/2019 